\title{
Performance of Phosphorus Adsorption by Acid-Activated Iron-Based Waterworks Sludge Adsorbent
}

\author{
J. X. Tie*(**), Y. F. Niu*, H. Xiao***, Y. S. Wang*, C. B. Du****, M. Zhang*, J. M. Zhang* and \\ Z. H. Zheng*****†
}

* School of Environmental and Municipal Engineering, North China University of Water Resources and Electric Power, Zhengzhou, 450045, PR China

**ZZhong Zhou Water Holding Co. Ltd., Zhengzhou, 450000, PR China

***B Bureau of Hydrology and Water Resources in Henan Province, Zhengzhou, 450004, PR China

****College of Chemistry and Chemical Engineering, Xi' an Shiyou University, Xi' an 710065, PR China

*****Henan Vocational College of Water Conservancy and Environment, Zhengzhou 450008, PR China

$\dagger$ Corresponding author: Z. H. Zheng; 15202843@qq.com

Nat. Env. \& Poll. Tech.

Website: www.neptjournal.com

Received: $14-05-2020$

Revised: 18-07-2020

Accepted: 20-07-2020

\section{Key Words:}

Acid-activated iron-based

waterworks sludge

(AAIBWS)

Phosphorus adsorption

Influencing factors

\begin{abstract}
Iron-based waterworks sludge was activated using $0.5-3 \mathrm{~mol} / \mathrm{L} \mathrm{H}_{2} \mathrm{SO}_{4}$ acid to obtain the acid-activated iron-based waterworks sludge (AAIBWS). The sludge treated with $1 \mathrm{~mol} / \mathrm{L} \mathrm{H}_{2} \mathrm{SO}_{4}$ acid was best for phosphorus adsorption and used to carry out batch phosphorus adsorption experiments. The influencing factors including solution $\mathrm{pH}$, contact time and reaction temperature were investigated. The results indicated that the acid environment was favourable for $\mathrm{P}$ adsorption. The phosphorus adsorption increased with the rising reaction time and temperature. The pseudo-second-order equation was best to describe the adsorption process among the three kinetic models. The Langmuir isotherm provided a better fit of the data than the Freundlich model. Thermodynamic parameters showed that the phosphorus adsorption on AAIBWS-1 had a spontaneous and endothermic nature.
\end{abstract}

\section{INTRODUCTION}

Phosphorus (P) discharged from industrial, agricultural sections and household is a limiting nutrient that causes eutrophication. It was reported that more than $60 \%$ of the lakes have been eutrophicated in China (Pan et al. 2004). The most stringent discharge standard for ' $\mathrm{P}$ ' has been set as $0.5 \mathrm{mg} / \mathrm{L}$ for the effluent discharged from the municipal sewage treatment plants to reduce the eutrophication in the water bodies accepting the effluent.

Chemical, physical and biological technologies have been developed to remove phosphorus from wastewater (Chang et al. 2017, Liu et al. 2018, Braun et al. 2019). Among the technologies, adsorption has attracted special concern due to its advantages such as low cost, high efficiency and simple operation.

Globally, the coagulation/flocculation process is used to produce drinking water in surface water treatment works. Aluminium and iron salts are two chemical coagulants used widely to remove turbidity from raw water (Faisal et al.
2020). During the coagu-flocculation process, the hydrolysed coagulants react with the suspended solids and colloids to form the flocs which settle down in the sedimentation tank, resulting in the generation of a large quantity of waterworks sludge globally (Fang et al. 2019, Faisal et al. 2020, Shrestha et al. 2020, Wang et al. 2018). The sludge contains coagulant residual, silica, clay minerals, and dissolved organic matters (Kang et al. 2019). Currently, the sludge is mainly dewatered and disposed of in landfills subsequently (Zhao et al. 2011), whereas, more and more landfills refuse to accept the dewatered waterworks sludge due to the scarce land resources and stringent environmental requirements in China. Hence, recycling and reuse of waterworks sludge is a promising way to deal with the massive sludge.

Acid activation could significantly enhance the porosity, surface area and roughness of the particles (Zhu et al. 2018, Lian et al. 2020), and increase the adsorption capacity subsequently. As a result, iron-based waterworks sludge was acid-activated and used as an adsorbent to remove ' $\mathrm{P}$ ' from its aqueous solution in this study. 


\section{MATERIALS AND METHODS}

Iron-based waterworks sludge: The iron-based waterworks sludge was collected from a drinking water treatment plant in Liaoning province, China. The collected sludge was dried in the open air and at $105^{\circ} \mathrm{C}$ in a drier for $2 \mathrm{~h}$ in sequence. The sludge was cooled and sieved through an 80 mesh sieve. $40 \mathrm{~g}$ sifted sludge powder was mixed with $400 \mathrm{~mL}$ of $0.5-$ $3 \mathrm{~mol} / \mathrm{L} \mathrm{H}_{2} \mathrm{SO}_{4}$ acid, and the mixture was reacted at $90^{\circ} \mathrm{C}$ for $2 \mathrm{~h}$. The mixture was then processed using alternate treatment of centrifugation at $4000 \mathrm{rpm}$ for $5 \mathrm{~min}$ and washed with deionized water several times until the supernatant became neutral. The activated sludge was re-dried at $105^{\circ} \mathrm{C}$ for $2 \mathrm{~h}$. Finally, the dried acid-activated iron-based waterworks sludge (AAIBWS) was collected for the experiment.

Characterization of AAIBWSs: A scanning electron microscope (JSM- 6460LV, Japan Electronic Co., Ltd.) was used to record the surface morphologies of AAIBWSs. The surface area was measured using the Brunauer-Emmett-Teller (BET) method of $\mathrm{N}_{2}$ adsorption and desorption (Autosorb-I, Quantachrome, USA). The chemical compositions of AAIBWSs were analysed using an X-ray fluorescence spectrometer (XRF, Model ARL PERFORM'X, Thermo Fisher Scientific Inc.).

'P' adsorption studies: Batch experiment of ' $\mathrm{P}$ ' adsorption was conducted in the following way: $10 \mathrm{~mL}$ P-containing solution and $0.08 \mathrm{~g}$ sludge were added into a glass bottle and reacted in a shaker at different temperatures for various times given explicitly in the following experiments. At the end of the reaction, the mixture was taken out and filtered through a $0.45 \mu \mathrm{m}$ filter membrane and the residual ' $\mathrm{P}$ ' in the supernatant was determined using the ascorbic acid method. The 'P' uptake was calculated using the following equation

$$
q=\frac{\left(C_{0}-C_{e}\right) V}{m}
$$

Where $\mathrm{q}(\mathrm{mg} / \mathrm{g})$ is the ' $\mathrm{P}$ ' uptake by per unit mass of the sludge. $\mathrm{C}_{0}$ and $\mathrm{C}_{\mathrm{e}}(\mathrm{mg} / \mathrm{L})$ are the initial and final ' $\mathrm{P}$ ' concentrations, respectively and ' $\mathrm{m}$ ' $(\mathrm{g})$ is the mass of AAIBWS used in the experiment. Each adsorption test was repeated three times, and the mean value of the three results was used in this article. The experimental errors were calculated and expressed with error bars.

\section{RESULTS AND DISCUSSION}

Characterization of the AAIBWS: Fig. 1 shows the SEM images of AAIBWSs treated with $\mathrm{H}_{2} \mathrm{SO}_{4}$ solutions of different concentrations. It can be seen clearly that the raw sludge had the largest particle size of about $30 \mathrm{~nm}$ which decreased to about $20 \mathrm{~nm}$ as the $\mathrm{H}_{2} \mathrm{SO}_{4}$ solution concentration rose to
Tab1e 1: The main compositions and specific areas of AAIBWSs.

\begin{tabular}{|c|c|c|c|c|c|}
\hline \multirow{2}{*}{$\begin{array}{l}\mathrm{H}_{2} \mathrm{SO}_{4} \\
\text { concentration } \\
(\mathrm{mol} / \mathrm{L})\end{array}$} & \multicolumn{4}{|c|}{ Oxide content ( wt $\%)$} & \multirow{2}{*}{$\begin{array}{l}\text { Specific } \\
\text { surface } \\
\text { area }\left(\mathrm{m}^{2} / \mathrm{g}\right)\end{array}$} \\
\hline & $\mathrm{Fe}_{2} \mathrm{O}_{3}$ & $\mathrm{SiO}_{2}$ & $\mathrm{Al}_{2} \mathrm{O}_{3}$ & $\mathrm{MoO}_{3}$ & \\
\hline 0 & 83.54 & 8.66 & 3.24 & 1.02 & 81.41 \\
\hline 0.5 & 82.77 & 9.63 & 3.13 & 1.28 & 130.59 \\
\hline A-1 & 80.37 & 11.54 & 3.45 & 1.39 & 140.32 \\
\hline 2 & 69.84 & 19.35 & 5.29 & 1.7 & 78.12 \\
\hline 3 & 25.66 & 55.12 & 12.07 & 0.299 & 51.93 \\
\hline
\end{tabular}

$3 \mathrm{~mol} / \mathrm{L}$ since more iron compounds dissolved in $\mathrm{H}_{2} \mathrm{SO}_{4}$ solution of higher concentration which was also the main reason that caused the decrease of the content of iron compounds of acid-activated AAIBWSs (Table 1). The specific surface area of raw sludge was $81.41 \mathrm{~m}^{2} / \mathrm{g}$ that increased to $140.32 \mathrm{~m}^{2} / \mathrm{g}$ after acid treatment by $1 \mathrm{~mol} / \mathrm{L} \mathrm{H}_{2} \mathrm{SO}_{4}$ acid, and then decreased to $51.93 \mathrm{~m}^{2} / \mathrm{g}$ as the $\mathrm{H}_{2} \mathrm{SO}_{4}$ concentration increased to $3 \mathrm{~mol} / \mathrm{L}$.

Effect of $\mathrm{H}_{2} \mathrm{SO}_{4}$ concentrations on AAIBWS adsorption capacity: Fig. 2 shows the effect of $\mathrm{H}_{2} \mathrm{SO}_{4}$ concentrations on the adsorption capacity of AAIBWSs. 'P' adsorption on raw sludge was $2.36 \mathrm{mg} / \mathrm{g}$ that increased to $3.79 \mathrm{mg} / \mathrm{g}$ as the $\mathrm{H}_{2} \mathrm{SO}_{4}$ concentration increased to $1 \mathrm{~mol} / \mathrm{L}$, and then decreased to $0.63 \mathrm{mg} / \mathrm{g}$ dramatically with the rising $\mathrm{H}_{2} \mathrm{SO}_{4}$ concentration to $3 \mathrm{~mol} / \mathrm{L}$. The ' $\mathrm{P}$ ' adsorption of AAIBWSs has same trend as their specific areas, indicating that the specific area is very crucial for ' $\mathrm{P}$ ' adsorption on AAIBWS. AAIBWS treated with $1 \mathrm{~mol} / \mathrm{L} \mathrm{H}_{2} \mathrm{SO}_{4}$ (AAIBWS-1) solution was used to carry out the following experiments.

Effect of solution $\mathbf{p H}$ on ' $\mathbf{P}$ ' adsorption: Fig. 3 shows the effect of solution $\mathrm{pH}$ on the ' $\mathrm{P}$ ' adsorption on AAIBWS-1. In the $\mathrm{pH}$ range of 3-6, the ' $\mathrm{P}$ ' adsorption was very stable and changed only from $7.15 \mathrm{mg} / \mathrm{L}$ to $7.26 \mathrm{mg} / \mathrm{L}$, and decreased to $6.32 \mathrm{mg} / \mathrm{L}$ at $\mathrm{pH} 7$, and further decreased to $6.02 \mathrm{mg} / \mathrm{L}$ at $\mathrm{pH} 10$. The results indicated that the acid environment was favourable for 'P' adsorption.

Kinetic study: Fig. 4 shows the effect of reaction time on AAIBWS-1 at two initial ' $P$ ' concentrations. Each curve contains both a fast and a slow adsorption stage. Both of the two fast stages lasted from the beginning of the experiment to the 15th min when AAIBWS-1 had more free active sites to make fast adsorption, whereas, the reaction slowed down due to less active sites and the competition between ' $P$ ' in the solution and ' $P$ ' on the AAIBWS-1 surface in the following slow stage.

Three kinetic models including pseudo-first-order, pseudo-second-order, and Elovich equations are adopted to fit the data as shown in Fig. 4. The models are shown as follows:

$$
\log \left(q_{e}-q_{t}\right)=\log q_{e}-\frac{k_{1}}{2.303} t
$$



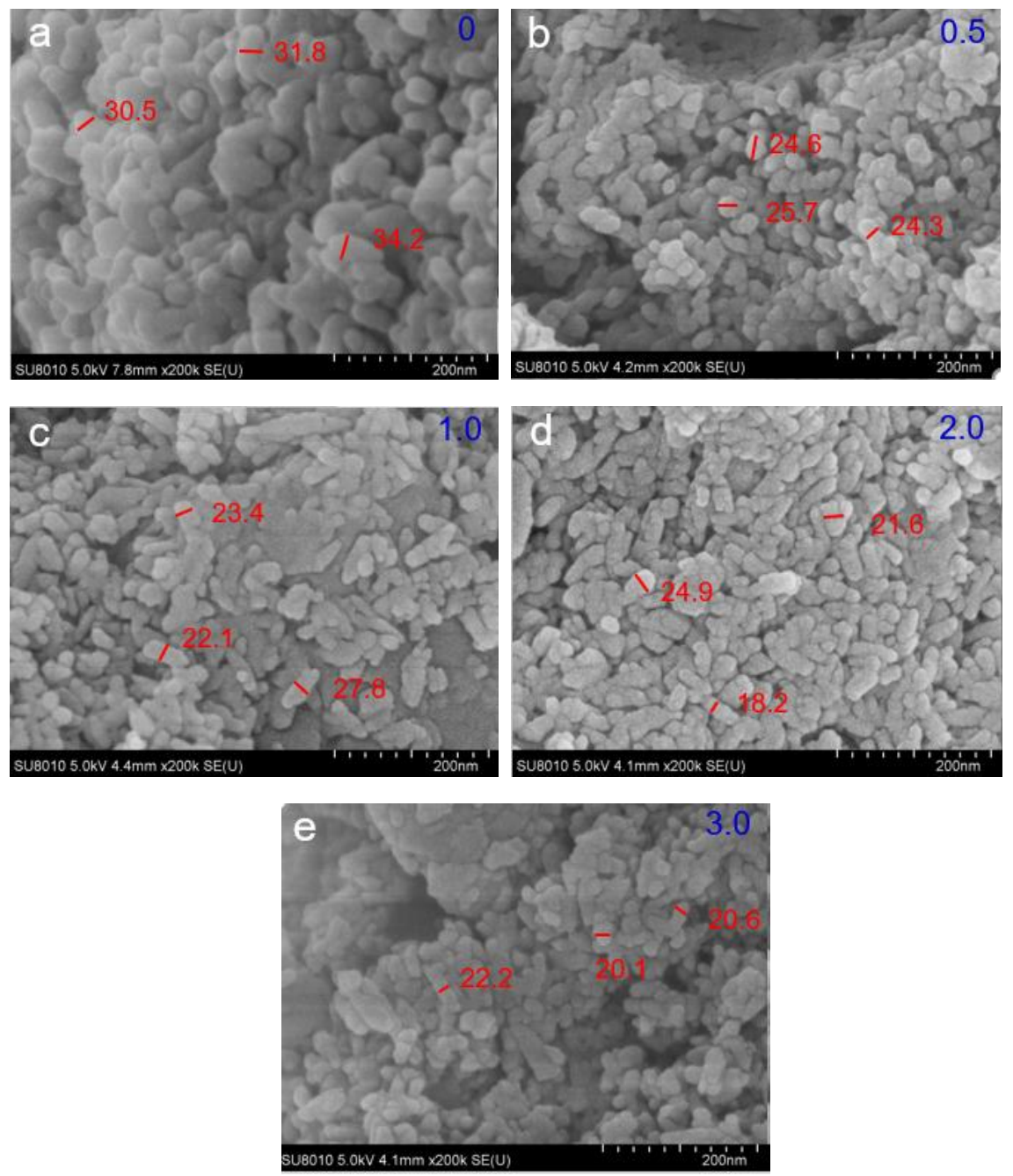

Fig.1: SEM images of AAIBWS treated with $\mathrm{H}_{2} \mathrm{SO}_{4}$ solution of different concentrations (a- $0 ; \quad b-0.5 ; \quad c-1 ; \quad$ d-2; e-3).

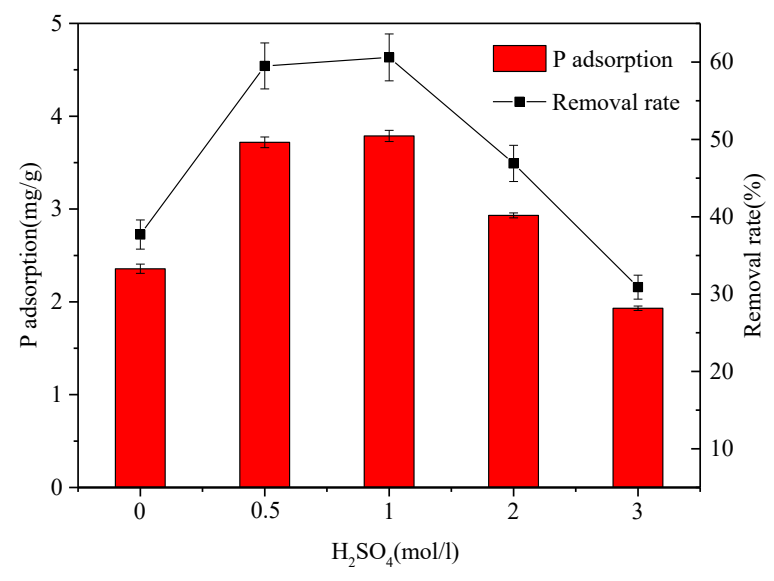

Fig. 2: Effect of $\mathrm{H}_{2} \mathrm{SO}_{4}$ concentrations on the $\mathrm{P}$ adsorption on AAIBWSs $\left(\mathrm{C}_{0}=50 \mathrm{mg} / \mathrm{l}\right.$, Time $=220 \mathrm{~min}$, Temperarture $\left.=30^{\circ} \mathrm{C}\right)$

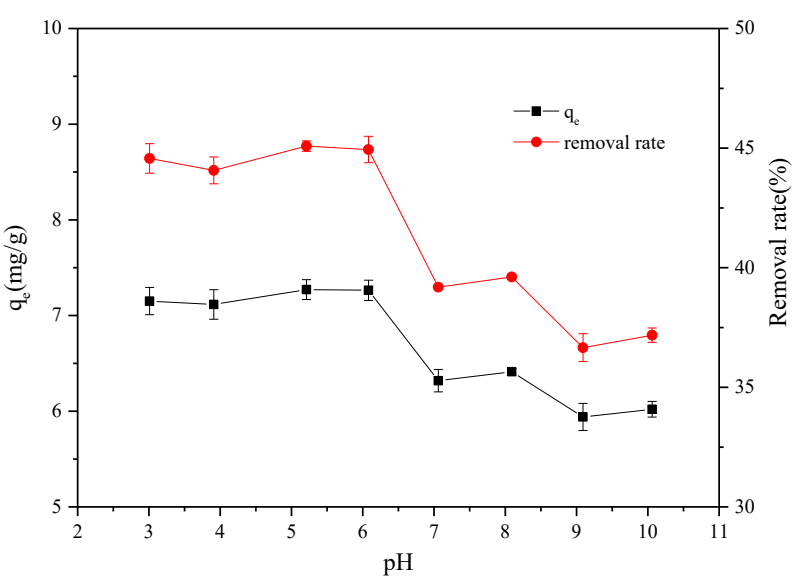

Fig. 3: Effect of solution $\mathrm{pH}$ on' $P$ ' adsorption on AAIBWS-1 $\left(\mathrm{C}_{0}=130 \mathrm{mg} / \mathrm{L}\right.$, Time $=600 \mathrm{~min}$, Temperarture $\left.=30^{\circ} \mathrm{C}\right)$ 


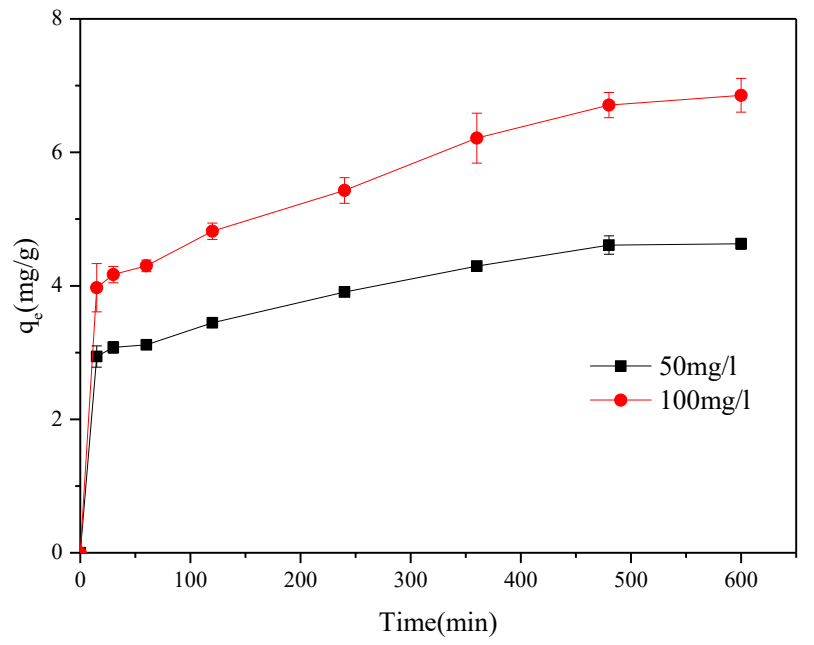

Fig. 4: Effect of reaction time on ' $P$ ' Adsorption on AAIBWS-1 (Temperarture $=30^{\circ} \mathrm{C}, \mathrm{pH}=7$ ).

$$
\begin{gathered}
\frac{t}{q_{t}}=\frac{t}{q_{e}}+\frac{1}{k_{2} q_{e}^{2}} \\
q_{t}=\frac{1}{\beta} \ln (\alpha \beta)+\frac{1}{\beta} \ln t
\end{gathered}
$$

Where $q_{t}$ and $q_{e}(\mathrm{mg} / \mathrm{g})$ are the ' $P$ ' adsorption at time $t$ and at equilibrium respectively. Both $\mathrm{k} 1\left(\mathrm{~min}^{-1}\right)$ and $\mathrm{k} 2 \mathrm{~g} /(\mathrm{mg}$ $\mathrm{min}$ )] are the equilibrium rate constants for pseudo-first-order and pseudo-second-order kinetic models, respectively. $\alpha[(\mathrm{mg} /(\mathrm{g} \mathrm{min})]$ is the initial adsorption rate and the cont stant associated with the fraction of surface coverage, and $\beta(\mathrm{g} / \mathrm{mg})$ is the activation energy for chemisorption, respectively.

As given in Table 2, the correlation coefficients of the pseudo-second-order equation are highest among the three equations, indicating the pseudo-second-order equation was best to describe the adsorption process.

Adsorption isotherms: Adsorption isotherm models are very important to understand the adsorption mechanisms. Hence, Langmuir and Freundlich models were used to fit the data shown in Fig. 5. The linearized forms of the two models are shown as the following equations, respectively:

$$
\frac{c_{e}}{q_{e}}=\frac{1}{q_{m} b}+\frac{c_{e}}{q_{m}}
$$

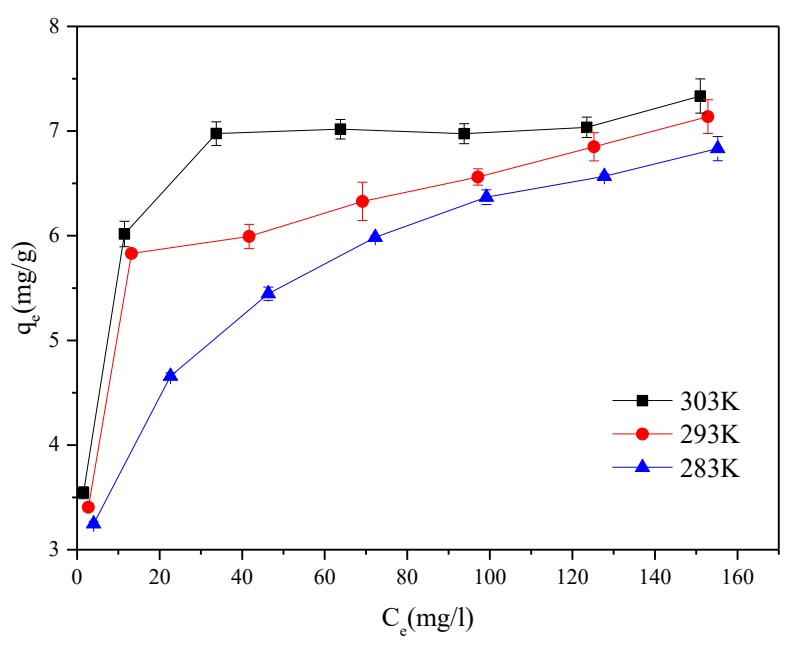

Fig. 5: Relationship between 'P' adsorption capacity and its equilibrium concentration at different temperatures $($ Time $=1440 \mathrm{~min}, \mathrm{pH}=7)$.

$$
\log q_{e}=\log k_{f}+\frac{1}{n} \log c_{e}
$$

Where $c_{\mathrm{e}}(\mathrm{mg} / \mathrm{L})$ and $q_{\mathrm{e}}(\mathrm{mg} / \mathrm{g})$ are the concentration and adsorption capacity at equilibrium, respectively. ' $b$ ' $(\mathrm{L} / \mathrm{mg})$ is the Langmuir constant related to binding energy, and $q_{\mathrm{m}}(\mathrm{mg} / \mathrm{g})$ is the maximum adsorption capacity. $k_{\mathrm{f}}$ is the Freundlich constant related to adsorption capacity, and ' $n$ ' is adsorption intensity.

As given in Table 3, the correlation coefficients of the Langmuir equation at all three temperatures are higher than those of the Freundlich equation indicating that the Langmuir equation was better to describe the adsorption process and the nature of monolayer adsorption (Khan et al. 2020).

Thermodynamic studies: The obtained experimental data were analysed using the following three equations to calculate the thermodynamic parameters.

$$
\begin{gathered}
\Delta G^{0}=\Delta H^{0}-\mathrm{T} \Delta S^{0} \\
\ln K=\frac{\Delta S^{0}}{R}-\frac{\Delta H^{0}}{R T} \\
K=\frac{q_{e}}{c_{e}}
\end{gathered}
$$

Where $\mathrm{K}$ is the distribution coefficient $(\mathrm{L} / \mathrm{kg}) ; \Delta S^{\circ}$ is the standard entropy change $(\mathrm{kJ} / \mathrm{mol} \cdot \mathrm{k}) ; \Delta H^{\circ}$ is the standard enthalpy change $(\mathrm{kJ} / \mathrm{mol}) ; R$ is the ideal gas constant

Table 2: The parameters of the three kinetic equations for ' $\mathrm{P}$ ' adsorption on AAIBWS-1.

\begin{tabular}{|llllllllll|}
\hline $\begin{array}{l}\mathrm{C}_{0} \\
(\mathrm{mg} / \mathrm{L})\end{array}$ & \multicolumn{2}{l}{ Pseudo-first-order equation } & \multicolumn{3}{c}{ Pseudo-second-order equation } & \multicolumn{3}{c|}{ Elovich equation } \\
\cline { 2 - 11 } & $\mathrm{q}_{\mathrm{e}}$ & $\mathrm{k}_{1}$ & $R^{2}$ & $\mathrm{q}_{\mathrm{e}}$ & $\mathrm{k}_{2}$ & $R^{2}$ & $\mathrm{a}$ & $\mathrm{k}_{3}$ & $R^{2}$ \\
\hline 50 & 2.28 & 0.0058 & 0.9571 & 4.78 & 0.0070 & 0.9947 & 1.35 & 0.4945 & 0.9165 \\
100 & 4.28 & 0.0066 & 0.9332 & 7.09 & 0.0037 & 0.9909 & 1.32 & 0.8204 & 0.9101 \\
\hline
\end{tabular}


Table 3: The parameters of Langmuir and Freundlich isotherm for $\mathrm{P}$ adsorption on AAIBWS-1.

\begin{tabular}{|lllllll|}
\hline \multirow{2}{*}{$\begin{array}{l}\text { Reaction } \\
\text { Temperature }\end{array}$} & \multicolumn{2}{l}{ Langmuir } & \multicolumn{4}{l|}{ Freundlich } \\
\cline { 2 - 7 } & $\mathrm{q}_{\mathrm{m}}$ & $\mathrm{b}$ & $R^{2}$ & $\mathrm{k}_{\mathrm{f}}$ & $\mathrm{n}$ & $R^{2}$ \\
\hline $10^{\circ} \mathrm{C}$ & 7.14 & 0.09 & 0.9958 & 2.46 & 4.87 & 0.9985 \\
$20^{\circ} \mathrm{C}$ & 7.19 & 0.17 & 0.9964 & 3.22 & 6.17 & 0.8815 \\
$30^{\circ} \mathrm{C}$ & 7.30 & 0.42 & 0.9990 & 3.70 & 6.76 & 0.8735 \\
\hline
\end{tabular}

Table 4: The thermodynamic parameters of 'P' adsorption on AAIBWS-1.

\begin{tabular}{|lllllr|}
\hline \multirow{2}{*}{$\mathrm{q}_{\mathrm{e}}$} & $\Delta \mathrm{H}^{0}$ & $\Delta \mathrm{S}^{0}$ & \multicolumn{4}{l|}{$\Delta \mathrm{G}^{0}(\mathrm{~kJ} / \mathrm{mol})$} & \\
\cline { 4 - 6 }$(\mathrm{mg} / \mathrm{kg})$ & $(\mathrm{kJ} / \mathrm{mol})$ & $(\mathrm{kJ} / \mathrm{mol} \cdot \mathrm{k})$ & $283 \mathrm{~K}$ & $293 \mathrm{~K}$ & $03 \mathrm{~K}$ \\
\hline 2000 & 54.77 & 0.24 & -14.38 & -16.82 & -19.27 \\
4000 & 55.45 & 0.24 & -13.22 & -15.64 & -18.07 \\
6000 & 58.37 & 0.24 & -10.83 & -13.27 & -15.72 \\
\hline
\end{tabular}

(8.314 $\mathrm{J} \mathrm{mol} / \mathrm{k})$; $\mathrm{T}$ is the reaction temperature $(\mathrm{K}) ; \Delta G^{\circ}$ is the standard Gibbs free energy change $(\mathrm{kJ} / \mathrm{mol})$.

As given in Table 4, the negative values of $\Delta G^{\circ}$ at the three temperatures indicated the spontaneous nature of ' $\mathrm{P}$ ' adsorption process, and the decreasing $\Delta G^{\mathrm{o}}$ values with the rising temperature suggested that higher temperature was favourable for the 'P' adsorption process. The positive $\Delta H^{\circ}$ revealed the endothermic nature of the ' $\mathrm{P}$ ' adsorption process, leading to better ' $\mathrm{P}$ ' adsorption at the higher temperature.

\section{CONCLUSION}

Iron-based waterworks sludge was treated with $0.5-3 \mathrm{~mol} / \mathrm{L}$ $\mathrm{H}_{2} \mathrm{SO}_{4}$ acid solution to improve its ' $\mathrm{P}$ ' adsorption capacity, and $1 \mathrm{~mol} / \mathrm{L} \mathrm{H}_{2} \mathrm{SO}_{4}$ acid solution was proved to be best for the activation. Batch adsorption experiments were conducted to investigate the ' $\mathrm{P}$ ' adsorption of AAIBWS-1. The results indicated that AAIBWS-1 had a larger 'P' adsorption capacity in the acid environment than in the alkaline environment. The pseudo-second-order equation was better than the pseudo-first-order equation and Elovich equation to describe the 'P' adsorption on AAIBWS-1. Langmuir isotherm was better than Freundlich isotherm to fit the experimental data, and the thermodynamic parameters indicated that ' $\mathrm{P}$ ' adsorption on AAIBWS-1was spontaneous and endothermic.

\section{ACKNOWLEDGEMENT}

We gratefully thank the support for this project by the Science and Technology major project of Henan Province [Grant number 161100310700]

\section{REFERENCES}

Braun, J.C.A., Borba, C. E., Godinho, M., Perondic, D., Schontaga, J.M. and Wenzel, B.M. 2019. Phosphorus adsorption in Fe-loaded activated carbon: Two-site monolayer equilibrium model and phenomenological kinetic description. Chem. Eng. J., 361: 751-763.

Chang, H.M., Chen, Sh.S., Nguyen, N.C., Chang, W.S. and Ray, S.S. 2017. Osmosis membrane bioreactor-microfiltration with magnesium based draw solute for salinity reduction and phosphorus recovery. Inter. Biodeter. Biodegr., 124: 169-175.

Faisal, A. A.H., Al-Wakel, S. F.A., Assi, H. A., Naji, L. A. and Naushad, Mu. 2020. Waterworks sludge-filter sand permeable reactive barrier for removal of toxic lead ions from contaminated groundwater. J. Water Process Eng., 33: 101-112.

Fang, X.L., Wang, L., Poon, C.S., Baek, K., Daniel, C.W., Tsang, D.C.W. and Kwok, S. K. 2019. Transforming waterworks sludge into controlled low-strength material: Bench-scale optimization and field test validation. J. Environ. Manage., 232: 254-263.

Kang, S., Choi, J.H., Park, J.G. and Baek, K. 2019. Pellet adsorbent derived from molasses and dewatered alum sludge for arsenic removal. Journal of $\mathrm{CO} 2$ Utilization, 33: 31-36.

Khan, Z. H., Gao, M.L., Qiu, W.W., Islam, M. S. and Song, Z.G. 2020. Mechanisms for cadmium adsorption by magnetic biochar composites in an aqueous solution. Chemosphere, 246: 1-9.

Lian, J.J., Zhou, F.J., Chen, B., Yang, M., Wang, S.H., Liu, Z.L. and Niu, S.P. 2020. Enhanced adsorption of molybdenum (VI) onto drinking water treatment residues modified by thermal treatment and acid activation. J. Clean Prod., 244: 1-11.

Liu, H., Yang, Y.K., Sun, H.F., Zhao, L. and Liu. Y. 2018. Effect of tetracycline on microbial community structure associated with enhanced biological N\&P removal in sequencing batch reactor. Bioresource Technol., 256: 414-420.

Pan, J.R., Huang, C. and Lin, S. 2004. Re-use of freshwater sludge in cement making. Water Sci. Technol., 9: 183-188.

Shrestha, S., Kulandaivelu, J., Sharma, K., Jiang, G.M. and Yuan, Z.G. 2020. Effects of dosing iron- and alum-containing waterworks sludge on sulfide and phosphate removal in a pilot sewer. Chem. Eng. J., 387: 1-13.

Wang, L., Zou, F.L., Fang, X.L., Tsang, D. C.W., Poon, C.S., Leng, Z. and Baek, K. 2018. A novel type of controlled low strength material derived from alum. Constr. Build. Mater., 165: 792-800.

Zhao, Y.Q., Doherty, L.P. and Doyle, D. 2011. Fate of water treatment residual: an entire profile of Ireland regarding beneficial reuse. Int. J. Environ. Stud., 68(2): 161-170.

Zhu, J.X., Zhang, P., Wang, Y.B., Wen, K., Su, X.1., Zhu, R.L., He, H.P. and Xie, Y.F. 2018. Effect of acid activation of palygorskite on their toluene adsorption behaviors. Appl. Clay Sci., 159: 60-67. 